\title{
On the Scales of Photographic Abstraction
}

\section{Andrew Fisher, Goldsmiths, University of London}

\begin{abstract}
This article explores three key ways in which questions of abstraction have been and continue to be closely associated with photography: the tradition of photographs that desire to 'be' abstract; the invisible but determining forms of abstraction central to capitalism and shaping of photography as a technical-historical form; and the technical-conceptual abstractions embedded in and structuring of photographic apparatuses. The exploration of these themes is pursued through analysis of Vilém Flusser's philosophy of photography, Lambert Wiesing's analysis of abstract photography and Allan Sekula's critique of capitalist modes of equivalence and exchange as these impact on the photographic.

These analyses are pursued through exploration of the issues, processes and operations of 'scale', 'scaling' and 'scalability' entailed in these three modes of abstraction and in their critical and theoretical reflection. The aim of this strategy is to outline and to analyse the complex web of abstractions that are central to photography and the modes of scale that are crucial to abstraction in this context. The article suggests that to encounter or to think about abstraction photographically is to operate within some modulation of scale and that this may in fact be the closest one can get to envisioning the complexity of abstraction in the photographic context.
\end{abstract}

\section{Photography's modes of abstraction}

What are the ways in which abstraction has been and might continue to be of concern for photography? Two answers are familiar: on the one hand, there those photographs or techniques that abstract from the apparently defining tasks of photography, to figure and to represent things, and, on the other hand, the invisible but determining forms of abstraction central to capitalism and shaping of photographic appearances and uses. I would add to these a third, less often cited, register of abstraction in photography, namely, those largely invisible elements of photographic apparatuses that serve to enable both the representational or non- 
representational uses towards which they are oriented and through which the abstractions of capitalism find material photographic form. Vilém Flusser's theorisation of the calculable conditions of the photographic articulates these conditions in terms of a concatenation of technical-scientific concepts, protocols and material conventions that are sedimented in photographic apparatuses and structuring of their ability to produce photographic images. ${ }^{1}$

At risk of only skimming the surface of each, this article attempts to hold all three of these modes of abstraction in view. A suspicion orients this strategy: that the current understanding of abstraction's on-going association with photography will remain limited unless one returns to thinking about such various registers in relation to one another. And this suspicion arises from existing discourse on abstraction and photography. Writing about 'abstract photographs' often only seems to produce end-game rehearsals of their status as art and also tends towards over-extended formalisations of both abstraction and photography. Critical accounts of the universalised forms of social abstraction playing across the surfaces of images often seem challenged by change in the expansive and intensifying relations they question. Accounts of the calculable nature of the photographic apparatus often seem overwhelmed by a pessimism in which the apparatus seems fated apriori to conquer all.

This article approaches the task of thinking about photography and abstraction through discussion of three examples that are helpful in avoiding the pitfalls just described. Vilém Flusser's philosophy of photography has already been named as one focus. Lambert

Wiesing's analysis of abstract photography and Allan Sekula's critique of capitalist modes of equivalence and exchange will be the basis of the following two. But before going on to consider them, the questions framing these discussions should be clarified.

\section{Abstraction - Photography - Scale}

The task of this article is to explore the issues, processes and operations of 'scale', 'scaling' and 'scalability' entailed in the three modes of abstraction noted above. Two intuitions guide this exploration: that a complex web of abstractions is central to photography and that the modulation and variation of scale in photography is central to abstraction in this context. I suggest that to encounter or to think about abstraction photographically is to operate within some modulation of scale and that this may in fact be the closest one can get to envisioning the complexity of abstraction in the photographic context. But following through 
on this suggestion entails an expansion in and a complication of what the term scale might mean. $^{2}$

The strategy is to take a step to one side to view photography through the prism of those senses of scale already harboured in its modes of abstraction. Attention to variations in the senses of scale entailed by these abstractions might enable one to delineate that which articulates and gives flesh to photography's part in capitalism's abstraction of social value, that grants significance to those moments at which photography eschews its normative representational and figural functions, and that renders the sense in which every photographic image is anticipated by a concatenation of abstract calculations.

An initial transposition of the three registers of abstraction sketched above into scaled terms might re-describe some of their important features as follows. What one is dealing with is the massive 'scale' of the photographic as such and as its forms and processes impinge on lived experience, with the modes and effects of 'scaling' foregrounded by image-objects that seek to free themselves photographically from representation, and with the operations of 'scalability' inscribed in the photographic apparatus as these render the world photographable. The term scale, in this context, thus borrows from debates about the production of space in political geography and critical art. It denotes phenomenological and material processes of encounter with photographic objects, apparatuses and the situations they structure. It refers one to basic photographic functions, the ways in which its sets things in temporally and spatially scaled relation to one another. Photography seems peculiar insofar as it appears to hinge on, produce and reproduce all of these modes and meanings of scale simultaneously.

The proposal here is to project links between each of these photographic modes of abstraction and such issues and forms of scale, scaling and scalability. The intuitions to be developed are that scale is a register of abstraction in photography - perhaps that it can be thought of as the phenomenal form taken by abstraction in photographic terms - and that issues of scale are crucial to each of the modes of abstraction indicated above. Thinking of these in their scalar aspects might enable one to hold their intertwined character in view and to evaluate what this means for the relationship between abstraction and photography more generally.

The background premise informing this is that, in one way or another, some process of, or encounter at scale - some orchestration of the different scales indicated - is always involved in any act, process, experience, object or machinery of photography. Risking an overly formal inversion, one might say that without its variously scaled characteristics and values, its 
operations of scaling, the propensity of its objects to be scaled, de-scaled and re-scaled, its setting of ostensible things to scale, its inscription in spatially and temporally scaled relations and the ways in which these are bound within hugely scalable infrastructures, there would be no photography.

So, you are being asked to entertain the notion that one or other combination of facts, operations and phenomena of scale is a necessary feature of all photography and that this fact is significant. A varying and ubiquitous operation of different senses of scale, modes of scaling, scaled phenomenon and conditions of scalability traverse the machinery, processes, uses and experiences that comprise the sprawling terrain of the photographic and, I argue, can be taken as a constant for photography. ${ }^{3}$

The relationship between photography and abstraction placed in question here hinges on the projection of a parallel to the way in which I have previously articulated three significant ways in which issues of scale appear integral to photography. These can be summarised as follows:

- That photographs set space and time together and to scale in the form of an image.

- That, whilst photographic images tend to take fixed seeming material forms, these are contingent moments on a sliding scale of possible actualisations.

- That photography not only has a substantial globalised scale but that its geopolitical import is grounded in and through the scaling operations and processes it operates within and serves to facilitate. ${ }^{4}$

These different modes of scale meet each other, so to speak, in the photograph. ${ }^{5}$ One might go so far to say that qua images photographs exist in or emerge from the tension between these intercalated and simultaneously operative horizons of scale, scaling and scalability. Implications to be drawn from this are that photography's representational character as a visual image form, questions of the materiality and/or immateriality of the photographic image and photography's expanding and increasingly intensified roles in the global order of contemporary capitalism are bound up with one another in ways that invite conceptualisation as modes of photography's variegated scales. And the meeting of these in 
the photograph, I argue, registers the process of photography's intertwined modes of abstraction as they take on form.

\section{Abstraction and scalability}

As it appears integral to the other modes of abstraction identified in the introduction, I will turn first to Vilém Flusser's theorisation of photography. Flusser's writings on photography offer a salutatory critical account of the forms and operations of calculation that he sees at work in photographic images, which set the terms for whatever photography gives to be seen and the experiences that photographs might elicit. What is of concern here is the manner in which he sees photography as being conditioned by the concatenated operation of technical-scientific concepts, protocols and material conventions sedimented in the photographic apparatus.

For Flusser, such features anticipate photographic images and their possible uses. They inform the photographic apparatus, are defining of its operation and thus set the parameters of what might be pictured photographically: 'The camera is programmed to produce photographs and every photograph is a realization of one of the possibilities contained within the programme of the camera' ${ }^{6}$

Famously, for Flusser, images are 'significant surfaces' that signify 'something [...] in space and time that they have to make comprehensible to us as abstractions'. ${ }^{7}$ The way that photographic images, in particular, do this is layered with further abstractions. Like other images, the photograph is an abstraction from the perceptual form of things. But the elements of a photograph bear a more highly mediated correspondence with that which they combine to stand for. And, crucially, this mediation presents itself in and as the photograph's immediate appearance. The process of making a photographic image is one in which its programmed conditions make themselves invisible, but continue in this mode of invisibility to haunt what might be made of any representation they present to view. The immediacy of photographic appearances harbours these technical conditions as their defining abstraction.

The product of an imaging apparatus, the technical image, presents a significant surface that Flusser distinguishes from traditional images (such as paintings) insofar as nontechnical image forms bear marks of their making out of which one is supposed to be able to read 'directly' the actions of its maker. Whether or not one finds this convincing as an understanding of the image forms Flusser names traditional, it does serve to project and fill 
out what is distinctive about the technical image, which is by contrast 'indirect'. The indirect form of the technical image arises from the fact that an apparatus shaped by 'scientific texts' produces it. ${ }^{8}$ This concatenation of applied theories (such as those of mechanics, computing and optics) can be understand in scaled terms by taking the camera as an example.

The fact that photographs might be taken to be representations at all derives from variable and associated technical processes organised into an apparatus that is oriented to set the appearance of things in scaled relation to one another, such as through the control of focus, exposure and aperture. Spatial and temporal relationships between things are thus registered through a predetermined combination of explicit scaling functions that both offer and circumscribe a range of possibilities according to which orders and ratios of scale - for instance, relative size and position, surface area and overlap, acuity and blur - are established in the making of a photographic image. The resulting image tends to efface these operations by directing attention towards the appearance of what it might depict. It pretends, so to speak, to be directly interpretable whilst also harbouring hidden operations that circumscribe what can be imaged and how. The form and the operations in question here are explicitly scaled and through this scale accrues an expansive sense.

In their scaling operation and in their scaled results photographic apparatuses produce what one might call a doubled visualisation of abstraction: firstly, in the sense of abstracting from the perceptual form of things to constitute their image and, secondly, as an expression of the underlying theoretical framework of the apparatus or as, in effect, the production of a representational image that is also a visualisation of the particular combination of invisible operations that enabled its making.

One never encounters anything represented in and by photography - whether places, things, moments or events - other than through a combination of processes that set salient aspects of appearance to scale in the more or less enduring but also changeable material form of an image. These scaling operations not only afford the photographic image's representational effects, they are also determined as conditions by the various bodies of technical knowledge and commercial interest governing the industries producing photographic apparatuses and the technologized image cultures these economic processes facilitate and seek to exploit. Here is a register of the third general characterisation of scale made in relation to photography: the operation of photography at a global scale and its complex and multiple scaling operations. Though it goes against the grain of Flusser's own vocabulary, one can note here that the concatenation of functions that comprise the 
apparatus's programmed character is marked by the Marxian forms of both 'real' and 'social' abstraction, and the register of their overlapping relation is the meeting of these different scaling operations in the particular scale found by an image-object and the orienting possibilities structuring the array of equipment that produced it. ${ }^{9}$

Though discussions of Flusser don't tend to remark the fact, his theory of photography is inherently scaled. ${ }^{10} \mathrm{He}$ articulates the notion of apparatus as an explicit question of scale in a section of the book Post History called 'Our Shrinking', which describes processes of scaling associated with the consolidation of technically articulated social relations. ${ }^{11}$ Contrasting the gigantic and monstrous proportions of key modern apparatuses (such as the machine and the city and their systems of relation) with a technologically facilitated movement towards 'miniaturisation', he criticises the tendency to see, in the small-scale economies of relation enabled by increasingly automated and autonomously acting programmed technologies, an alternative to a spectre of the large-scale 'megalomania of the apparatus'. ${ }^{12}$ The kinds of autonomy promised by 'intelligent instruments' equipped with 'mini-programmes' are always already inscribed in a totality to the effect that small-scale possibilities are determined by the way they 'work within and in function of gigantic apparatus'. ${ }^{13}$ As he writes elsewhere in the same book: 'In such an environment we are all played players, Homines ludentes' ${ }^{14}$

The most intimate, immediate or fixed seeming experience of photography, in particular those arising from connections between micro and macro level processes in contemporary photographic apparatuses, is shot through with such scaled relations and the implications Flusser draws out of them. Scalability is decisive for the relational operation of this apparatus as it knits together affects and technical processes on the intersubjective terrain of contemporary photographic usage. But this can also be said of even those moments of photography that seem most divorced from the worldliness of representation and the social relations it figures.

\section{Abstract Photography}

The self-conscious pursuit of an 'abstract' photography has a long history, a core tendency of which takes the form of variations on a desire to turn photography to the production of non-representation and non-figuration. ${ }^{15}$ This highlights a defining tension in the idea of abstract photography that can be simply expressed. Setting out not to picture things 
with photography, to 'free' it from representation, foregrounds the photographic status of its creations. As Gottfried Jäger has it in his essay 'Abstract Photography' what is projected by this desire is a, 'different photography, one which does not refer to a reality outside the picture, as is always the case with likenesses and symbolic images. Instead, it only refers to itself., ${ }^{16}$ This formalist sentiment is often repeated in discussions of abstract photography and the function of auto-referentiality it projects is generally supposed to act as guarantee for the artistic status of the resulting image-object and to reveal, in an auto-poetic manner, something essential about photography. ${ }^{17}$

It is against this formalist backdrop that Lambert Wiesing's 'What Could "Abstract Photography" Be?' analyses the idea that it can only proceed by abstracting from one or more of the conventional functions of the photographic apparatus. ${ }^{18}$ With regard to the representational and figural logic of photography this entails a sliding scale of technicalhistorical renunciations that bring photography to its limits: starting out with the removal of pictorial content, camera and lens from the photographic process and extending to the absence of an object interposed between light source and light sensitive surface (photograms, lumigrams and chemigrams are his examples here). ${ }^{19}$ For Wiesing, these variations on the abstract photograph concentrate attention on infrastructural elements that normally efface themselves when a photographic image presents something to be seen. As an image-object the abstract photograph foregrounds the visualisation of the absence of representation and figuration and thus makes emphatic the technical-material structures through which this absence finds manifestation. In this respect he writes:

The problem of abstract photography, remarkably, is not the simple statement that it does not display a recognizable object, but the giving of reasons why and for what an abstract photo abstracts from the depiction of a familiar object. The solution to this problem is related to the phenomenon [...] that every abstraction happens in order to direct attention to something that is judged to be essential. When we abstract, we disregard something and thereby show that we think we can disregard it. Thereby, in turn, we show that what we disregard, from our point of view, cannot be essential, since essential things can, in principle, not be disregarded. That is why every abstraction always leads to an exhibition of what is deemed essential; every abstracting turning away is linked to a visualizing turn toward. ${ }^{20}$ 
This sets up his threefold answer to the question of what abstract photography could be. It might forego the conventions of display 'for the sake of image-immanent structures', 'mere visibility' or 'object art'. ${ }^{21}$ The important difference between the abstraction from and display of something, here, lies in their relative directedness: 'outwards' towards the world of photographable things or 'inwards' to the conditions that enable this depiction but also its suspension. And it is this metaphor of doubled and rhythmically articulated turning that, I think, saves Wiesing's analysis from the pitfalls of aesthetic formalism which otherwise undercut the interest of discourse on abstract photographs. Only the abstract photograph, for Wiesing, makes manifest that 'we cannot create a photo that does not develop visible structures' and that 'the structures and forms that we see in abstract photography [...] are the structures and forms that could display something but display nothing, ${ }^{22}$ Yet, he is careful not to hypostatise that which might be 'deemed essential' in the process, to make it into a crudely determined essence deriving from one or other discreet aspect of photography. The actual linkages between what an 'abstracting turning away' and a 'visualizing turn toward' turn upon remains contingent and variable and the care with which Wiesing articulates this makes his analysis of abstract photography productive.

But what of scale here? Starting from the second of my general observations on the scaled character of the photographic one might reappraise Wiesing's account of the abstract photograph. The singular status of the abstract photographic art objects he defends seems to stand in in stark opposition to the labile and contingent infrastructural processes, which make these objects possible and that underpin their claim to significance. ${ }^{23}$ Their often otherwise interesting characteristics notwithstanding, such works tend to foreground the operation of combined infrastructural processes whilst hypostatising these into a static form that is supposed to crystallise something essential about photography. Non-pictorial visualisations of what is deemed essential in the process foreground surface and pattern, tonal contrast, apparent depth relations, blur and sharpness and the manner in which these results stand in relation to one another on the bounded surface of the image-object. Such features, I argue, act as visualisations of the broadly conceived scaling operations articulated above as these characterise the infrastructural operations that may be placed in question. One might say that, divorced of their representational function, abstract photographs do nothing but scale, show that they have scaled and, importantly, that they remain open to further scaling in ways that undercut their apparent autonomy. 
Furthermore, what thinking about abstract photographs in formalist terms tends not to acknowledge is that along with the evacuation of outside reference they tend to deny the other modes of abstraction to which they are subject and which the refiguration of their autoreferential - zero-degree - visualisation in scaled terms might help to reinscribe them with. One might think of the fact that, as image-objects, they remain open as possibilities of scaling in Benjaminian terms and that this would reintroduce questions of the alienation of value - of their abstracted commodity form - that the formalist self-description seems concerned to deny. In being set within circuits of reproduction, for instance, they remain as open to processes of de- and re-scaling as all other photographic images. Though it might seem supplementary, I argue that it is not actually extra to their existence as photographic works, it is integral to it insofar as this is a photographic possibility, much in the mode of Benjamin's observation that the aura of the artwork dissolves in the face of technical reproduction. ${ }^{24}$ Abstract photographs attain their formalised status as art through what turns out to be a heavily ironic play on the very conditions that threaten this status. Viewed through the prism of scale the essentialist formalism associated with abstract photographs becomes an ironised marker of the sliding scales of possible actualisation to which all photographs are subject and this sets them within a horizon of determining social abstractions. By forgetting the social abstraction of value that contextualises them, their claim to abstraction becomes contradictory.

Here, we can return to Wiesing's claim that infrastructural elements of photography revealed by an abstraction from the functions of the apparatus are variable but necessary, always and operative but contingent. The significance of such elements is constitutively fluid and labile, not located in any particular process but in the fact that what ever form it takes photography is always constituted as a combination of processes that are oriented to register and to show something. If one were to divorce this from the formalist concern to reduce photography down to an absence of representation one might read Wiesing as having shown that such uses of photography are refinements and extensions of a generic propensity common to all photographic apparatuses and implied by all photographic images: that a basic function of photography is to register the ostensible spatial and temporal state of things, to fix these together at certain scales of relation and according to a combination of prefigured operations of scale and anticipations of scaled outcomes. Given that the operations described here are the locus, the meeting point of different meanings of scale in and for photography, the contingent modes and possibilities of 'abstracting turning away' and 'visualizing turning toward' that stand to reveal abstraction only multiply. The abstractions performed by abstract photography 
thus stand out as second-order modes of abstraction resting on strategies aimed at disambiguating photography's propensity for setting things to scale and the different registers of abstraction that already attend this.

\section{Abstraction and the Scaling of Photographic Materiality}

The forms and processes of abstraction integral to capitalism impinge upon all of the senses of abstraction discussed above. There is, as John Roberts recently remarked: ' no photography — no photographic imaginary — that lives, or might live, on the other side of its effects. ${ }^{25}$ Allan Sekula's analyses of the forms of abstraction shaping of photography stand as a powerful critique of this fact. And a key focus of his work is its analysis of photography's promise to act as a universal language, which, as is well known, reveals the form of such universality to be determined by pervasive ideologies of abstract equivalence and exchangeability. His essay 'Photography Between Labour and Capital' of 1983 articulates this powerfully and in a way that still resonates today. ${ }^{26}$

Tracing the relationship between mimetic equivalence, universal exchangeability and calculation in the historical statements of François Arago and Oliver Wendell Holmes, Sekula observes - firstly, with respect to Arago's often quoted announcement of photography's invention - that:

Photography doubly fulfilled the Enlightenment dream of a universal language: the universal mimetic language of pictures yielded up a higher truth, a truth that could be expressed in the universal abstract language of mathematics. ${ }^{27}$

And this dream of a 'photographically mathematized nature' quickly found economic expression in Oliver Wendell Holmes's projection of a world encompassing encyclopaedic photographic archive in which, Sekula continues:

The meaning and value of the photograph ultimately resides in its exchangeable character, its inclusion within this global archive which translated all sights, all visions, into relations of formal (and mathematical) equivalence. Holmes saw the photograph as the stripping of form from matter, and foresaw "a universal currency of these banknotes ... which the sun has engraved for the great Bank of Nature.” 
Metaphorically, he made the connection between photographic representation, quantification, and commodity exchange. Photography submitted the world to a uniform logic of representation, just as the global market established a uniform logic of exchange. ${ }^{28}$

These connections, Sekula goes on to point out, indicate photography's absorption into what Georg Simmel termed 'the calculating character of modern times'. ${ }^{29}$

Sekula's analyses of particular images, discourses of photography, photographic practices and institutions have left us with a number of detailed and specific critiques of this generalised logic of abstraction and its calculative form. What this article can attempt to do, in coming towards its conclusion, is to offer a brief and supplementary articulation of some of these questions of abstraction drawing on the questions of scale discussed above. This, it is hoped, will be suggestive of ways of making new critical linkages between, for instance, the political geographies shaping of the photographic, their scaling operations and the scaled character of the photographic images, apparatuses and modes of experience that emerge and circulate within them.

One point of purchase for such a scaling of photographic abstraction arises from the recent and ongoing technological transformation of photography and its persistence as a globally important form despite or perhaps because of these changes. At risk of oversimplification, on the one hand, this situation only serves to intensify and make more obvious the fact that photographic apparatuses, images, experiences and uses are subject to the generalised forms of abstraction Sekula describes and that have no 'life' as Roberts remarks 'on the other side of' the effects of abstraction. On the other hand, the massive expansion and intensification entailed in this processes has brought with it new forms and infrastructures through which such abstraction operates, which many have taken to mean that the broad forms and effects of capitalist abstraction familiar from Sekula's critical project no longer apply and that, as a result photography has become immaterial in form. ${ }^{30}$

Here, one can return again to the three modes of photographic scale outlined above to remark that the function of setting space and time together and to scale in the form of an image is indisociable from their actualisation as contingent moments on a sliding scale of possible actualisations and that these operations are grounded in and through processes unfolding at a global social scale. 
All photographies necessarily find some kind of material form, however attenuated or dispersed, and, I argue, it is useful to think of this in terms of the ways in which they take on scale. This is of particular interest for attempts to understand the networked digital image and its apparent immateriality, often posited in contrast to the familiar material forms of earlier photographic convention. The networked digital image may, indeed, be defined by the fact that it can choose not to take on such forms. But it takes on form nonetheless in being distributed across different spaces, through dispersed infrastructures and experiential registers, the balance between which is obviously and highly changeable. Here, as Peter Osborne observes: 'There is no single site of the photograph. [...] There is a distributive unity to the photograph itself. ${ }^{31}$ The networked digital condition of photography disperses the material form of the photograph, the ontological significance of which was often previously assumed to be located in and by one or other material substrate (such as the negative). Taking on such distributed form means that the photograph is no longer definable by one or other familiar material substrate, if it ever was. Out of this, the photograph emerges as a spatially and temporally extended process. But it is material insofar as it takes on scale across its different and changeable sites of distribution. The analysis of scale pursued above outlines it's meaning as just such a process, and it too is one that can no longer be thought of as rooted in a particular and privileged object or relation.

The networked digital image takes form as a variegated, compound and modally organised relationship of scales and it obviously does so in ways that are different from the pre-digital photograph. Whilst it still finds materiality at photographic scale it also rests on a radical innovation in photographic scale insofar as this is revealed to be mutable, variegated and distributive in form. Such images attain their materiality as variations on a possible admixture of dispersed scales with significant technical, phenomenological and global as well as perceptual, local and embodied registers. One might risk saying, in this context at least, that photographic materiality is the taking on of the admixture of the various scalar modes comprising of and supporting the image and its uses. And into this newly reconfigured admixture of photography's scaled relations the tensions between its modes and understandings of abstraction are reinscribed.

The specific mutations that mark the 'calculating character' of present times, and its photographic modulation of the abstractions exchangeability and equivalence, have produced newly universalised relationships between what the 'mimetic language of pictures' and the 'abstract language of mathematics' might continue to mean. These mutations entail and have 
foregrounded obvious and not so obvious issues of scale. And these facts suggest the need for a re-evaluation of the modes of abstraction common to the photographic in terms of its mutating modes of scale.

By way of brief conclusion one can note that the three associations between abstraction and photography explored in this article are significantly shaped and/or oriented towards questions of scale. Whilst the three general observations about scale and photography discussed in parallel to them do not map neatly or singularly on to any one of the questions of abstraction considered, all three scaled aspects of the photographic do touch upon each of the modes of abstraction discussed and enable connections to be made between them. Thinking about photography and abstraction in terms of scale has complicated the meaning of the latter term considerably. It has also, it is hoped, suggested itself as a fruitful theoretical and critical figure, and a productive way of making connections between otherwise discreet levels of practice and forms of thinking about the photographic and its on-going association to ideas of abstraction.

${ }^{1}$ Vilém Flusser, Towards a Philosophy of Photography, Reaktion Books, London, 1983. See also his essay, 'Towards a theory of techno-imagination', Philosophy of Photograph y, vol. 2, no. 2, 2012, pp. 195-201.

${ }^{2}$ For a more detailed discussion of these issues see my, 'Photographic Scale', in On the Verge of Photography: Imaging Beyond Representation, A. Fisher, J. Golding \& D. Rubinstein (eds.), Birmingham, ARTicle Press, 2013, pp. 151-170.

${ }^{3}$ See my 'Scale the Photographic Horizons', in Too Big To Scale, ZHdK, Zurich (forthcoming, 2016).

${ }^{4}$ Fisher, 'Photographic Scale', p. 156.

${ }^{5}$ The discussion here draws closely on Peter Osborne's recent theorization of the photograph as a 'distributive unity'. See, Peter Osborne, 'Photographic Ontology, Infinite Exchange' in Anywhere or Not At All, Verso, London and New York, 2013, pp. 117-132.

${ }^{6}$ Flusser, Towards a Philosophy of Photography, p. 26.

${ }^{7}$ Ibid, p. 8.

${ }^{8}$ Ibid, p. 14.

${ }^{9}$ See John Roberts gloss on these terms in relation to photography in, Photography and its Violations, Columbia University Press, New York, 2014, p. 94. Roberts devotes much of this book to a discussion of the modes abstraction takes in photography and, in particular, to the 'catachreisistic relationship between the figural and the nonfigural' as this is mediated by the:

overlapping forms of social abstraction (the material and symbolic structures of domination expressed in the heteronomous character of the built environment, the 
social divisions of the landscape, and the repetitive, inertial logic of commodity relations) and real abstraction (the organization of production and consumption through the discipline of the value-form, the internalization and naturalization of the value-form as "free competition"), p. 93.

${ }^{10}$ One exception is the following gloss on Flusser's conception of the apparatus from Matthew Fuller: 'Here, iterations of multi-scalar relations of causality and interpenetration are compiled layer upon layer. Base and superstructure shot through a kaleidoscope. Programs and metaprograms are never clearly defined as distinct. The relation is simply one of scale, or of order'. Matthew Fuller, Media Ecologies: Materialist Energies in Art and Technoculture, Cambridge, MA: MIT Press, 2005, p. 2.

${ }^{11}$ Flusser, Post-History, 2013, pp. 75-90. See also his, 'Orders of Magnitude and Humanism' in Vilém Flusser: Writings, Andreas Stroel (ed.), Erik Eisel (trans.), University of Minnesota Press, Minneapolis\& London, 2002, pp. 160-164.

${ }^{12}$ Ibid, p. 76.

${ }^{13}$ Ibid, p. 77

${ }^{14}$ Ibid, p. 104.

${ }^{15}$ Lambert Wiesing remarks Alvin Langdon Coburn's use of the term in 'The Future of Pictorial Photography' in 1916 as probably the first explicit use of the term abstract photography. Alvin Langdon Coburn, 'The Future of Pictorial Photography', in Photograms of the Year, 1916, p. 23-24. See Lambert Wiesing, 'What Could "Abstract Photography" Be?' in Artificial Presence: Philosophical Studies in Image Theory, Nils F. Schott (trans.), Stanford University Press, Stanford California, 2010, p. 60.

${ }^{16}$ Gottfried Jäger, Abstract Photography', in Rethinking Photography I \& II: Narration and New Reduction in Photography, Ruth Horak (ed.), Fotohof Edition, Salzburg, 2003, p. 166.

${ }^{17}$ A canonical reference in this context is Lázló Moholy-Nagy. In 'A New Instrument of Vision' of 1936, for instance, he writes: 'the photogram, or camera-less record of forms produced by light, which embodies the unique nature of the photographic process, is the real key to photography'. Here, a familiar claim emerges, namely, that the relative 'directness', the lack of mediation characteristic of the process of making photograms and the uniqueness of its results combine to suggest that the photogram can be taken as photography in its most reduced and thus in its purist form. This reference highlights other ways in which abstract photography might be analysed in scalar terms and which there is no space to explore here as, for instance, with associations between the 1:1 ratio common to the minimalized representational possibilities of the photogram and the suggestion that this marks a 'zero degree' of photography. Lázló Moholy-Nagy, 'The New Vision', in The Photography Reader, Liz Wells (ed.), Routledge, London, 2002, pp. 92-96. See also Sandra Plummer's discussion of these issues from a Heideggerean point of view, 'Photogram', in Philosophy of Photography, vol. 3, no. 1, 2012, pp. 173-183.

${ }^{18}$ Wiesing, 'What Could “Abstract Photography” Be?', pp. 60-79.

${ }^{19}$ Ibid, pp. 65-68.

${ }^{20}$ Ibid, p. 70.

${ }^{21}$ Ibid, p. 79.

22 Ibid, p. 72.

${ }^{23}$ Gottfried Jäger is a key example here. See Gottfried Jäger, Rolf. H. Krauss \& Beate Reese, Concrete Photography, Kerber Verlag, Bielefeld, 2005. 
${ }^{24}$ Walter Benjamin, 'The Work of Art in the Age of Mechanical Reproduction', in Illuminations, Hannah Arendt (ed.), Harry Zohn (trans.), New York, Schocken Books, 1968, pp. 217-64.

${ }^{25}$ Roberts, Photography and its Violations, p. 94.

${ }^{26}$ Allan Sekula, 'Photography Between Labour and Capital', in Mining Photographs and Other Pictures: A Selection from the Negative Archives of Sheddon Studio, Glace Bay, Cape Breton, 1948-1968, Halifax, Nova Scotia: Press of the Nova Scotia College of Art and Design, 1983. For a recent appreciation of the continuing critical resonances of this essay, see Alberto Toscano, 'Photography Against the Flow: Abstraction and Logistics in Allan Sekula's Writings' in Allan Sekula: Ship of Fools/Dockers Museum, Hilde Van Gelder (ed.), Leuven University Press, Leuven, 2015, pp. 45-54.

${ }^{27}$ Ibid, p. 219.

${ }^{28}$ Ibid, p. 219.

${ }^{29}$ Georg Simmel, The Philosophy of Money, pp. 443-446 as quoted by Sekula in "Photography Between Labour and Capital', p. 220.

${ }^{30}$ An interesting example of this tendency is Nathanial Cunningham's, Face Value: An Essay on the Politics of Photography, Workingroup, New York, 2012.

${ }^{31}$ Osborne, Anywhere or Not At All, p. 124. 